\title{
SUCCEED: Summer Center for Climate, Energy, and Environmental Decision Making
}

\author{
$\underline{\text { AUTHORS }}$ \\ * \\ 1 \\ 2 \\ 3
}

\section{ABTRACT}

Preparing a literate public to critically evaluate issues related to climate change, energy and the environment is an important pillar towards more sustainable societies. The Summer Center for Climate, Energy, and Environmental Decision-Making (SUCCEED) is a K-12 Outreach program created by - University's Department of Engineering and Public Policy (EPP). The program was originally proposed and created under the auspices of the Climate and Energy Decision Making Center (CEDM), a multi-institution collaborative agreement anchored at- University, and supported by the U.S. National Science Foundation. The program objectives are a) to improve scientific literacy by providing a free summer program focusing on climate, energy, and environmental decision-making for both students entering tenth grade, and K-12 teachers, b) encourage pursuit of STEM-related careers, and c) to help teachers prepare curriculum in this area to be used in class. SUCCEED consists of two programs: a five- day workshop with approximately twenty students entering 10th grade, and a two-day workshop with approximately ten math and science educators to improve teacher curriculum. SUCCEED has been held every summer from 2011 to 2016, and is planned to be held again in 2017. Through this submission, we plan to describe the general characteristics of SUCCEED, discuss program outcomes, and explore lessons learned.

SUCCEED is organized, directed, and taught primarily by volunteer $\mathrm{PhD}$ students. The student workshop is offered free of charge to participants, and includes interactive lectures, hands-on activities, and field trips. Although the exact program changes every year, similar core material is covered every year: understanding energy and power consumption around the home, how power plants work, life cycle assessment, climate science, and a series of modules on different conventional and renewable energy sources. Lesson plans and activities from the program are available to the general public, accessible online [1].

Participants in the teacher workshop receive a small honorarium for attending the program. A small number of readings are assigned in the month preceding the workshop. The 2-day workshop typically includes mornings of lectures on climate change and energy from $\mathrm{PhD}$ students or professors, followed by an afternoon of collaborative lesson planning based on the 
morning lectures. These lesson plans draw on material from the student workshop, and new ideas suggested by the teachers are likewise incorporated into future iterations of the student program.

Students and teachers provide feedback on all activities by responding to a standardized questionnaire at the end of their respective workshops. Common themes from this feedback will be discussed in this submission. Similarly, learning outcomes are measured by having SUCCEED participants (students and teachers) complete a knowledge assessment both before and after their respective workshops. As previously reported [2], both students and teachers showed a statistically significant $(\mathrm{p}<0.05)$ improvement in test scores each year from 2011 2014. This submission will also show updated results from 2015 and 2016 . Finally, we will discuss lessons learned, based on feedback provided each year by the rotating program directors.

\section{NOTE}

In the interest of full disclosure, a description of the program and many of these results is available in ref [2], and has been presented at past conferences (The Association of Environmental Engineering and Science Professors in 2015 and the American Geophysical Union in 2013).

\section{REFERENCES}

[1] Summer Center for Climate, Energy, and Environmental Decision-Making (SUCCEED) Lesson Plans: Leonard Gelfand Center. Available from: http://www.cmu.edu/gelfand/k12-teachers/succeed/index.html.

[2] Faria F, Klima K, Posen I D and Azevedo I M L 2015 A New Approach of Science, Technology, Engineering, and Mathematics Outreach in Climate Change, Energy, and Environmental Decision Making Sustainability: The Journal of Record 8 261-71 